\title{
Common mental disorders among patients attending monk healers and primary health care centres in Thailand: a cross-sectional study
}

Supa Pengpid ${ }^{1,2}$ and Karl Peltzer ${ }^{3^{*}}$ (1)

\begin{abstract}
Background: This study aimed to assess the rate of common mental disorders in patients consulting monk healers or health centres in Thailand.

Methods: Patients consecutively consulting monk healers or health centres were assessed with screening measures of three common mental disorders (major depressive, general anxiety and somatization disorder).

Results: The prevalence of any common mental disorder was significantly higher in patients attending monk healers (31.1\%) than those attending primary care health centres $(22.3 \%)(P<0.001)$. Likewise, the prevalence of each common mental disorder was significantly higher in clients attending monk healers (major depressive disorder 21.0\%, generalized anxiety disorder $8.1 \%$, and somatization disorder 19.0\%) than in patients attending health centres (major depressive disorder 15.8\%, generalized anxiety disorder 3.5\%, and somatization disorder 12.5\%). In adjusted logistic regression analysis among patients of monk healers, female sex, being single, divorced, separated or widowed, and low social support were associated with any common mental disorder. Among patients of a health centre, lower education, not employed, high debt status and low social support were associated with any common mental disorder.
\end{abstract}

Conclusion: The study found a higher prevalence of common mental disorders in patients consulting monk healers than primary care centre attendees, calling for integrated management of common mental disorders.

Keywords: Common mental disorders, Monk healer, Primary care, Thailand

\section{Background}

Traditional and faith healers have been identified as a workforce contributing to mental health care worldwide [1]. In a systematic review, traditional healers have shown to be beneficial in psychosocial interventions by reducing psychological distress and mild symptoms in common mental disorders (=CMD) [1]. Among non-communicable disease and mental disorder patients in Thailand, 26.3\% had been utilizing traditional and/or faith healing practitioners in the past 12 months [2]. Traditional health

*Correspondence: kfpeltzer@gmail.com

${ }^{3}$ Department of Psychology, University of the Free State, Bloemfontein, South Africa

Full list of author information is available at the end of the article practitioners that may include spiritual, monk, and herbal healers, are located in all different parts of Thailand [3]. Monk healers (maw pra) that reside at Buddhist temples provide various types of treatments to patients, including prayers and Thai traditional medicine $[4,5]$. Several studies $[6,7]$ have described the management of CMD by monk healers in Thailand [6, 7].

Studies investigating the prevalence of CMD in the traditional health practitioner setting and comparative studies in the primary health care system are scarce, in particular in Southeast Asia. Several studies on the prevalence of $\mathrm{CMD}$ in the traditional health practitioner setting have been conducted in Africa, e.g. in Kenya the prevalence of depression was $22.9 \%$ [8], in Tanzania, the prevalence of CMD was $48 \%$ (double that of primary 
care patients 24\%) [9], and in Uganda the prevalence of psychological distress was $65.1 \%$ [10]. A number of studies investigated the prevalence of CMD in a primary care setting in Asia, e.g., in Thailand, the prevalence of depression (mild to severe) was $11.5 \%$ [11], in Nepal, the prevalence of depression was $16.8 \%$ [12], in Kuwait the prevalence of CMD was $42.7 \%$ [13], in Singapore, the prevalence of major/minor depressive disorders was $9 \%$ [14], and in China, the prevalence of moderate or high somatic symptoms (PHQ-15: scores $\geq 10$ ) was $19.0 \%$, depression $15.2 \%$, anxiety $6.9 \%$, both depression and anxiety $5.2 \%[13]$.

Determinants of CMD of persons attending traditional health practitioners, include being older $[8,9]$, being female [8], single, divorced or separated $[8,9]$, Christian [9], lack of education [8], better educated [9], unemployed [8], lack of food and being in debt [10]. Determinants of CMD of persons attending primary health facilities include lack of social support and life stress [11]. This study aimed to assess the rate of CMD in patients presenting to monk healers or primary care health facilities in Thailand.

\section{Methods}

\section{Participants and procedures}

In a cross-sectional study design, adult patients attending primary care health centres or monk healers were systematically recruited (consecutive sampling) after written informed consent was obtained. Purposeful sampling was used to select three monk healers or temples and three primary health care centres located in four districts of the eastern and central region of Thailand. Inclusion criteria for the selection of the study sites were to have at least five patients a day, and the inclusion criteria for the selection of clients or patients was aged 18 years and above. The study was conducted from November 2018 to February 2019. A professional nurse conducted face-to-face interviews in Thai language with patients on background data and CMD. Questionnaires were pretested for validity on a sample of 30 patients, not included in the final sample. Research nurses were systematically trained in the administration of the questionnaires. Moreover, the assessment procedures and implementation were routinely monitored by senior research staff. Study approval was obtained from each of the study sites, and the study protocol was approved by the "Office of The Committee for Research Ethics (Social Sciences), Mahidol University (No.: 2017/055.1403)."

\section{Measures}

Sociodemographic data included marital status, education, sex, age, work status, religion, and economic status (extent of debt).
Social support was assessed with the "Oslo 3-items Social Support Scale (OSSS-3)", covering "the number of people the respondent feels close to, the interest and concern shown by others, and the ease of obtaining practical help from other." [16]. The total scores (3-14) were grouped into " $3-8=$ poor, $9-11$, = moderate, and 12-16 strong support” [14] (Cronbach's alpha 0.75 in this sample).

The Patient Health Questionnaire-9 (PHQ-9) was used to assess major depressive disorder (MDD)" [17]. "It has demonstrated high sensitivity (0.84) and specificity (0.77) in a validation study in Thailand, using a cut-off score of nine or more as indicative for MDD" [18] (Cronbach's alpha 0.88 in this sample).

The Generalized anxiety disorder 7-item (GAD-7) scale was used to measure "the severity of generalized anxiety, with a score of 10 or more indicating moderate or severe GAD" [19] (Cronbach's alpha 0.92 in this sample).

The Patient Health Questionnaire-15 somatic symptoms (PHQ-15) screened for somatization disorder [20]. "The somatic symptoms severity is calculated by assigning scores at 0,1 , and 2 to the response categories of not at all, bothered a little, and bothered a lot for the 15 somatic symptoms" [20]. As recommended in previous research [20-22], cut-off scores $\geq 10$ indicated moderate or high somatic symptom severity [20-22] (Cronbach's alpha 0.83).

\section{Data analysis}

Descriptive statistics (frequencies, percentages, means, and standard deviations) is used to show the prevalence of CMD and sample characteristics. Differences in proportions were tested with Pearson chi-square tests and parametric tests. Univariate and multivariable logistic regression analyses were utilized to estimate demographic and social determinants of CMD by health care settings. The data were analysed with IBM-SPSS for Windows, version 25 (Chicago, IL, USA).

\section{Results}

Sample and common mental disorder characteristics

The total sample consisted of 1251 patients, 51.5\% from health centres and $48.5 \%$ from monk healers; the overall response rate was $97 \%$. The proportion of female patients with the monk healers was $76.6 \%$ and with the health facility sites $72.5 \%$, respectively), and all patients were Buddhists by religion. Patients attending monk healers had higher socioeconomic status (education, less debt), social support and were younger than primary care attendees. The prevalence of any CMD was significantly higher in clients attending monk healers (31.1\%) than those attending primary care health centres (22.3\%) $(\mathrm{P}<0.001)$ (see Table 1$)$. 
Table 1 Sociodemographic and any common mental disorder characteristics of participants attending monk healers and primary care health centres $(\mathrm{N}=1251)$

\begin{tabular}{|c|c|c|c|c|c|c|}
\hline Variable & $\begin{array}{l}\text { Monk healer } \\
\text { Sample } \\
\text { M (SD) }\end{array}$ & $\begin{array}{l}\text { Health centre } \\
\text { Sample } \\
\text { M (SD) }\end{array}$ & $P$ value & $\begin{array}{l}\text { Monk healer } \\
\text { CMD } \\
\text { M (SD) }\end{array}$ & $\begin{array}{l}\text { Health centre } \\
\text { CMD } \\
M(S D)\end{array}$ & $P$ value \\
\hline \multirow[t]{2}{*}{ Age in years } & $47.3(13.8)$ & $53.3(14.1)$ & $<0.001$ & $45.1(13.5)$ & $56.2(14.4)$ & $<0.001$ \\
\hline & $N(\%)$ & N (\%) & & N (\%) & $N(\%)$ & \\
\hline All & $607(48.5)$ & $644(51.5)$ & & $181(31.1)$ & $138(22.3)$ & \\
\hline \multicolumn{7}{|l|}{ Sex } \\
\hline Female & $465(76.6)$ & $469(72.8)$ & 0.254 & $152(84.0)$ & $99(71.7)$ & 0.007 \\
\hline Male & $142(23.4)$ & $175(27.2)$ & & $29(16.0)$ & $39(28.3)$ & \\
\hline \multicolumn{7}{|l|}{ Formal education } \\
\hline Primary or less & $225(38.5)$ & $404(64.6)$ & $<0.001$ & $57(32.6)$ & $110(80.3)$ & $<0.001$ \\
\hline Secondary & $185(31.7)$ & $166(26.6)$ & & $63(36.0)$ & $21(15.3)$ & \\
\hline Post-secondary & $174(29.8)$ & $55(8.8)$ & & $55(31.4)$ & $6(4.4)$ & \\
\hline \multicolumn{7}{|l|}{ Marital status } \\
\hline $\begin{array}{l}\text { Single/divorced/sepa- } \\
\text { rated/widowed }\end{array}$ & $250(41.7)$ & $145(22.9)$ & $<0.001$ & $97(54.2)$ & $31(22.8)$ & $<0.001$ \\
\hline Married & $350(58.3)$ & $489(77.1)$ & & $82(45.8)$ & $105(77.2)$ & \\
\hline \multicolumn{7}{|l|}{ Employment status } \\
\hline No & $192(32.0)$ & $169(26.4)$ & 0.127 & $69(39.2)$ & $59(43.4)$ & 0.457 \\
\hline Yes & $408(68.0)$ & $467(73.6)$ & & $107(60.8)$ & $77(56.6)$ & \\
\hline \multicolumn{7}{|l|}{ In debt } \\
\hline No/little & $436(71.8)$ & $474(73.6)$ & 0.481 & $124(68.5)$ & $57(31.5)$ & 0.002 \\
\hline High & $171(28.2)$ & $170(26.4)$ & & $57(31.5)$ & $67(48.6)$ & \\
\hline \multicolumn{7}{|l|}{ Social support } \\
\hline Low & $106(17.7)$ & $106(16.7)$ & $<0.001$ & $49(27.1)$ & $49(35.8)$ & 0.201 \\
\hline Medium & $280(46.7)$ & $395(62.3)$ & & 75 (41.4) & $54(39.4)$ & \\
\hline High & $213(35.6)$ & $133(21.0)$ & & $57(31.5)$ & $34(24.8)$ & \\
\hline
\end{tabular}

$M$ mean, $S D$ standard deviation, $C M D$ common mental disorder

The prevalence of each CMD was significantly higher in clients attending monk healers (major depressive disorder $21.0 \%$, generalized anxiety disorder $8.1 \%$, and somatization disorder $19.0 \%)$ than in patients attending health centres (major depressive disorder $15.8 \%$, generalized anxiety disorder $3.5 \%$, and somatization disorder $12.5 \%)$. In addition, the prevalence of the combinations of having two or three different CMD was higher in clients attending monk healers than in patients attending health centres (see Table 2).

\section{Associations with any common mental disorder}

In adjusted logistic regression analysis, among clients of a monk healer, female sex, being single, divorced, separated

Table 2 Distribution of the type of common mental disorder by service facility

\begin{tabular}{lclr}
\hline Type of common mental disorder & $\begin{array}{l}\text { Monk healer } \\
\text { N (\%) }\end{array}$ & \multicolumn{1}{l}{$\begin{array}{l}\text { Health centre } \\
\text { N (\%) }\end{array}$} & $\begin{array}{r}\text { P value } \\
\text { Depressive disorder }\end{array}$ \\
Anxiety disorder & $123(21.0)$ & $99(15.8)$ & 0.021 \\
Somatization disorder & $48(8.1)$ & $22(3.5)$ & $>0.001$ \\
Depressive and anxiety disorder & $113(19.0)$ & $79(12.5)$ & 0.002 \\
Depressive and somatization disorder & $43(7.4)$ & $19(3.0)$ & $<0.001$ \\
Anxiety and somatization disorder & $60(10.3)$ & $42(6.7)$ & 0.027 \\
Depressive, anxiety and somatization disorder & $26(4.4)$ & $13(2.1)$ & 0.021 \\
\hline
\end{tabular}


or widowed, and low social support were associated with any CMD. Among patients of a health centre, lower education, not employed, high debt status, and low social support were associated with any CMD (see Table 3).

\section{Discussion}

The study found a higher prevalence of CMD among monk healers than primary care attenders. Similar results were found in a study in Tanzania [9]. The prevalence of $31.1 \%$ of any CMD among monk healer attenders was lower than the one found in Tanzania (48\%) [9], and Uganda (psychological distress) (65.1\%) [10], and the prevalence of depression (21.0\%) among monk healer attenders was similar to a study among traditional health practitioner attenders in Kenya (22.9\%) [8]. The prevalence of major depressive disorder was $15.8 \%$ among primary care attenders, which was a little higher than in a previous study in a primary care setting in Thailand (11.5\%) [11], and Singapore (9\%) [14], similar to China (15.2\%) [15] and Nepal (16.8\%) [12]. The prevalence of CMD among primary care attenders in this study (22.3\%) was lower than that found in Kuwait (42.7\%) [13], and the prevalence of somatization and generalized anxiety disorder among primary care attenders in this study (12.5\% and $3.5 \%$, respectively) was a little lower than found in China (19.0\% and 6.9\%, respectively) [15].

In agreement with some previous investigations [8, 9], this study found that female sex and being single, divorced, separated, or widowed were associated with the prevalence of any CMD in the monk healer setting. Furthermore, this study found that younger age was associated with CMD in the monk healer setting, while previous studies $[8,9]$ found that older age was associated with CMD in the traditional health practitioner setting. It is possible that monk healers, rather than traditional Thai health practitioners, similar to the use of complementary medicine, are more attractive to young and middle-class Thais [23]. Some previous studies [8-10] found that educational level, employment status, and economic status were associated with the prevalence of CMD in the traditional health care setting, while this study did not find such differences, only in unadjusted analysis, being unemployed was associated with any CMD in the monk healer setting. Lack of social support was in both care settings (monk and primary care) associated with $\mathrm{CMD}$, which was also found in the primary care setting

Table 3 Associations with any common mental disorder by health care setting

\begin{tabular}{|c|c|c|c|c|}
\hline \multirow[t]{2}{*}{ Variable } & \multicolumn{2}{|l|}{ Monk healer } & \multicolumn{2}{|l|}{ Health centre } \\
\hline & COR & AOR & COR & AOR \\
\hline Age in years & $0.98(0.97,0.99)^{* *}$ & $0.98(0.95,0.99)^{*}$ & $1.02(1.01,1.04)^{* *}$ & $1.00(0.98,1.01)$ \\
\hline \multicolumn{5}{|l|}{ Sex } \\
\hline Female & 1 (Reference) & 1 (Reference) & 1 (Reference) & 1 (Reference) \\
\hline Male & $0.27(0.18,0.41)^{* * *}$ & $0.53(0.32,0.88)^{*}$ & $0.31(0.22,0.44)^{* * *}$ & $0.88(0.54,1.25)$ \\
\hline \multicolumn{5}{|l|}{ Formal education } \\
\hline Primary or less & 1 (Reference) & 1 (Reference) & 1 (Reference) & 1 (Reference) \\
\hline Secondary & $1.56(1.01,2.41)^{*}$ & $1.26(0.74,2.14)$ & $0.38(0.23,0.63)^{* * *}$ & $0.37(0.19,0.70)^{* *}$ \\
\hline Post-secondary & $1.31(0.84,2.03)$ & $0.95(0.55,1.64)$ & $0.33(0.14,0.79)^{*}$ & $0.24(0.09,0.67)^{* *}$ \\
\hline \multicolumn{5}{|l|}{ Marital status } \\
\hline $\begin{array}{l}\text { Single/divorced/separated/ } \\
\text { widowed }\end{array}$ & 1 (Reference) & 1 (Reference) & 1 (Reference) & 1 (Reference) \\
\hline Married & $0.48(0.34,0.69)^{* * *}$ & $0.60(0.40,0.90)^{*}$ & $0.98(0.62,1.54)$ & $1.29(0.74 .2 .25)$ \\
\hline \multicolumn{5}{|l|}{ Employment status } \\
\hline No & 1 (Reference) & 1 (Reference) & 1 (Reference) & 1 (Reference) \\
\hline Yes & $0.63(0.43,0.92)^{*}$ & $0.68(0.44,1.04)$ & $0.36(0.24,0.54)^{* * *}$ & $0.51(0.31,0.85)^{* *}$ \\
\hline \multicolumn{5}{|l|}{ In debt } \\
\hline No/little & 1 (Reference) & 1 (Reference) & 1 (Reference) & 1 (Reference) \\
\hline High & $1.33(0.91,1.93)$ & $1.01(0.66,1.56)$ & $3.81(2.58,5.63)^{* * *}$ & $2.63(1.63,4.26)^{* * *}$ \\
\hline \multicolumn{5}{|l|}{ Social support } \\
\hline Low & 1 (Reference) & 1 (Reference) & 1 (Reference) & 1 (Reference) \\
\hline Medium & $0.43(0.27,0.67)^{* * *}$ & $0.54(0.33,0.89)^{*}$ & $0.27(0.17,0.67)^{* * *}$ & $0.24(0.14,0.42)^{* * *}$ \\
\hline High & $0.37(0.23,0.60)^{* * *}$ & $0.52(0.30,0.88)^{*}$ & $0.56(0.33,0.94)^{*}$ & $0.54(0.29,1.03)$ \\
\hline
\end{tabular}

COR rude odds ratio, $A O R$ adjusted odds ratio

***P $<0.001,{ }^{* *} \mathrm{P}<0.01,{ }^{*} \mathrm{P}<0.05$ 
in Thailand in a previous study [11]. Having lower education, being unemployment, and having high debt were associated with CMD in the primary care setting. This finding seems to show the good accessibility of primary health care centres, also them being free of charge. Furthermore, patients with CMD who are unemployed and have debt should be supported in employment seeking and debt relief.

Considering the high prevalence of CMD in the monk healer setting, it appears that monk healers are better placed to deal with CMD than primary health centres, which are the first population contact for preventive, promotive and basic curative care [24], in Thailand. More research is needed on the treatment approach of monk healers in relation to their diagnosis, management, and treatment outcomes of CMD, such as naturalistic prospective investigations [9]. Monk healers in Thailand could undergo training in evidence-based practices to help in reducing the mental health treatment gap, especially in rural communities [8].

\section{Study limitations}

CMD were only measured using several screening instruments. However, in future studies structured psychiatric interviews, such as with the SCID or SCAN, should be conducted, at least with the ones identified positive with the screening tool. Furthermore, we did not assess the history of health seeking behaviour to show which health system (monk healer, health centre, or other) was utilized serially or parallelly.

\section{Conclusion}

The study found a higher prevalence of CMD among monk healers than primary care attenders in Thailand, calling for integrated management of CMD. Future research should follow up patients presenting to monk healers and primary care health facilities with CMD in Thailand to evaluate treatment outcomes.

\begin{abstract}
Abbreviations
CMD: Common mental disorders; GAD: Generalized anxiety disorder; MDD: Major depressive disorder; OSSS-3: Oslo 3-items Social Support Scale; PHQ: Patient Health Questionnaire; SCAN: Schedules for Clinical Assessment in Neuropsychiatry; SCID: Structured Clinical Interview for Diagnostic and Statistical Manual for Mental Disorders.
\end{abstract}

\section{Acknowledgements}

The study received support from the Department of Higher Education, South Africa.

\section{Authors' contributions}

All authors fulfil the criteria for authorship. SP and KP conceived and designed the research, performed statistical analysis, drafted the manuscript, and made critical revision of the manuscript for key intellectual content. All authors read and approved the final version of the manuscript and have agreed to authorship and order of authorship for this manuscript.
Funding

The study received support from the Department of Higher Education, South Africa.

\section{Availability of data and materials}

The datasets used and/or analysed during the current study is available from the corresponding author on reasonable request.

\section{Ethics approval and consent to participate}

The study protocol was approved by the "Office of The Committee for Research Ethics (Social Sciences), Mahidol University (No.: 2017/055.1403)", and study permission was obtained from the study sites. Written informed consent was obtained from participants.

\section{Consent for publication}

Not applicable.

\section{Competing interests}

The authors declare that they have no competing interests.

\section{Author details}

${ }^{1}$ ASEAN Institute for Health Development, Mahidol University, Salaya, Phutthamonthon, Nakhon Pathom, Thailand. ${ }^{2}$ Department of Research Administration and Development, University of Limpopo, Turfloop, South Africa.

${ }^{3}$ Department of Psychology, University of the Free State, Bloemfontein, South Africa.

Received: 8 July 2020 Accepted: 29 October 2020

Published online: 04 November 2020

\section{References}

1. Nortje G, Oladeji B, Gureje O, Seedat S. Effectiveness of traditional healers in treating mental disorders: a systematic review. Lancet Psychiatry. 2016;3(2):154-70. https://doi.org/10.1016/S2215-0366(15)00515-5.

2. Peltzer K, Pengpid S, Puckpinyo A, Yi S, le Anh V. The utilization of traditional, complementary and alternative medicine for non-communicable diseases and mental disorders in health care patients in Cambodia, Thailand and Vietnam. BMC Complement Altern Med. 2016;16:92.

3. Adthasit R, Kulsomboon S, Chantraket R, Suntananukan S, Jirasatienpong $P$. The situation of knowledge management and research in the area of local wisdom in health care. In: Petrakard P, Chantraket R, editors. The report situations of Thai traditional medicine, indigenous medicine and alternative medicine 2005-2007. Nonthaburi: Mnat Films; 2007. p. 16-22.

4. Chan-iam W, Yodmalee B, Nakornriab M. Thai traditional medicine at Wat Nong Ya Nang Buddhist, Uthai Thani Province. JFHB. 2019;12(2):40-7.

5. Kaewla W, Wiwanitkit V. Local primary health care by local religious center: a case study of a Mahayana Buddhist temple, Thailand. Ann Trop Med Public Health 2015;8:226. https://www.atmph.org/text. asp?2015/8/5/226/159850.

6. Panyapchoto P. Buddhist approach to disease burring with mental treatment. JGRNSBC. 2013;2(1):26-7. https://www.journal.nbc.mcu.ac.th/.

7. Jilek-Aall $L$, Jilek WG. Buddhist temple treatment of narcotic addiction and neurotic-psychosomatic disorders in Thailand. In: Pichot P et al., editors. Psychiatry: the state of the art. New York: Springer; 1985. p. 673-77.

8. Musyimi CW, Mutiso VN, Musau AM, Matoke LK, Ndetei DM. Prevalence and determinants of depression among patients under the care of traditional health practitioners in a Kenyan setting: policy implications. Transcult Psychiatry. 2017;54(3):285-303. https://doi.org/10.1177/13634 61517705590.

9. Ngoma MC, Prince M, Mann A. Common mental disorders among those attending primary health clinics and traditional healers in urban Tanzania. Br J Psychiatry. 2003;183:349-55. https://doi.org/10.1192/bjp.183.4.349.

10. Abbo C, Ekblad S, Waako P, Okello E, Muhwezi W, Musisi S. Psychological distress and associated factors among the attendees of traditional healing practices in Jinja and Iganga districts, Eastern Uganda: a cross-sectional study. Int J Ment Health Syst. 2008;2(1):16. https://doi. org/10.1186/1752-4458-2-16.

11. Nuntatikul $P$, Hongsranagon P, Havanond P. Prevalence of and factors associated with depression in Thai adult general OPD patients 
at Phanomphrai Hospital, Roi-Et Province, Thailand. J Health Res. 2018;24(Suppl. 2):133-7. https://www.tci-thaijo.org/index.php/jhealthres/ article/view/157625.

12. Luitel NP, Baron EC, Kohrt BA, Komproe IH, Jordans MJD. Prevalence and correlates of depression and alcohol use disorder among adults attending primary health care services in Nepal: a cross sectional study. BMC Health Serv Res. 2018;18(1):215. https://doi.org/10.1186/s1291 3-018-3034-9.

13. Alkhadhari $\mathrm{S}$, Alsabbrri $\mathrm{AO}$, Mohammad IH, Atwan $\mathrm{AA}$, Alqudaihi $\mathrm{F}_{\text {, }}$ Zahid MA. Prevalence of psychiatric morbidity in the primary health clinic attendees in Kuwait. J Affect Disord. 2016;195:15-20. https://doi. org/10.1016/j.jad.2016.01.037.

14. Sung SC, Low CC, Fung DS, Chan YH. Screening for major and minor depression in a multiethnic sample of Asian primary care patients: a comparison of the nine-item Patient Health Questionnaire (PHQ-9) and the 16-item Quick Inventory of Depressive Symptomatology - SelfReport (QIDSSR16). Asia Pac Psychiatry. 2013;5(4):249-58. https://doi. org/10.1111/appy.12101.

15. Zhu C, Ou L, Geng Q, Zhang M, Ye R, Chen J, Jiang W. Association of somatic symptoms with depression and anxiety in clinical patients of general hospitals in Guangzhou, China. Gen Hosp Psychiatry. 2012;34(2):113-20. https://doi.org/10.1016/j.genhosppsych.2011.09.005.

16. Kocalevent RD, Berg L, Beutel ME, Hinz A, Zenger M, Härter M, Nater U, Brähler E. Social support in the general population: standardization of the Oslo social support scale (OSSS-3). BMC Psychol. 2018;6(1):31. https://doi. org/10.1186/s40359-018-0249-9.

17. Kroenke K, Spitzer RL, Williams JB. The PHQ-9: validity of a brief depression severity measure. J Gen Intern Med. 2001;16(9):606-13. https://doi.org/10 $.1046 / j .1525-1497.2001 .016009606 . x$.

18. Lotrakul M, Sumrithe S, Saipanish R. Reliability and validity of the Thai version of the PHQ-9. BMC Psychiatry. 2008;8:46. https://doi. org/10.1186/1471-244X-8-46.
19. Spitzer RL, Kroenke K, Williams JB, Lowe B. A brief measure for assessing generalized anxiety disorder: the GAD-7. Arch Intern Med. 2006;166(10):1092-7. https://doi.org/10.1001/archinte.166.10.1092.

20. Kroenke K, Spitzer RL, Williams JB. The PHQ-15: validity of a new measure for evaluating the severity of somatic symptoms. Psychosom Med. 2002;64(2):258-66. https://doi.org/10.1097/00006842-200203000-00008.

21. Körber S, Frieser D, Steinbrecher N, Hiller W. Classification characteristics of the Patient Health Questionnaire-15 for screening somatoform disorders in a primary care setting. J Psychosom Res. 2011;71(3):142-7. https:// doi.org/10.1016/j.jpsychores.2011.01.006.

22. Schaefert R, Höner C, Salm F, Wirsching M, Leonhart R, Yang J, Wei J, Lu W, Larisch A, Fritzsche K. Psychological and behavioral variables associated with the somatic symptom severity of general hospital outpatients in China. Gen Hosp Psychiatry. 2013;35(3):297-303. https://doi. org/10.1016/j.genhosppsych.2012.11.001.

23. Pengpid S, Peltzer K. Comparison of clients or patients attending monk healers and primary care clinics in Thailand: a cross-sectional study. JHSAM. 2020; 2(2):1-8. https://he01.tci-thaijo.org/index.php/jhealthsci alternmed/article/view/243870.

24. Tangcharoensathien V, Witthayapipopsakul W, Panichkriangkrai W, Patcharanarumol W, Mills A. Health systems development in Thailand: a solid platform for successful implementation of universal health coverage. Lancet. 2018;391(10126):1205-23. https://doi.org/10.1016/S0140 $-6736(18) 30198-3$.

\section{Publisher's Note}

Springer Nature remains neutral with regard to jurisdictional claims in published maps and institutional affiliations.
Ready to submit your research? Choose BMC and benefit from:

- fast, convenient online submission

- thorough peer review by experienced researchers in your field

- rapid publication on acceptance

- support for research data, including large and complex data types

- gold Open Access which fosters wider collaboration and increased citations

- maximum visibility for your research: over 100M website views per year

At BMC, research is always in progress.

Learn more biomedcentral.com/submissions 